\title{
"Se você não mudar, morrerá": a (con)formação de um trabalhador de novo tipo no discurso de autoajuda*
}

ADRIANA CLÁUDIA TURMINA

Serviço Nacional de Aprendizagem

Comercial, Florianópolis, SC, Brasil

ENEIDA OTO SHIROMA

Universidade Federal de Santa

Catarina, Florianópolis, SC, Brasil

\section{INTRODUÇÃO}

A autoajuda, muito mais que um fenômeno editorial de vendas, constitui-se em uma ideologia que difunde e desperta o imaginário de construção de um homem realizado, de sucesso, possuidor de riqueza e poder. Reforça a ideia de progresso individual ao mesmo tempo em que populariza e naturaliza a noção de mudança, adaptação, competição e mobilidade social como responsabilidades individuais. Tais concepções, disseminadas no senso comum, são introjetadas como verdades, contribuindo para a organização da cultura de uma época. Aconselhamentos, orientações, regras de conduta e fragmentos biográficos que visam ensinar o indivíduo a ser um trabalhador de novo tipo utilizam a linguagem da "administração pelos fatos" (Liker, 2005), uma linguagem pragmática que doutrina. Tal linguagem não é neutra, ao contrário, carrega uma determinada concepção de mundo (Gramsci, 1984, p. 11).

* Este trabalho deriva da tese intitulada Autoajuda nas relações de trabalho: a (con) formação de um trabalhador de novo tipo, defendida por Adriana Cláudia Turmina no Programa de Pós-Graduação em Educação/Universidade Federal de Santa Catarina (PPGE/ UFSC), sob orientação de Eneida Oto Shiroma. A tese foi contemplada com Menção Honrosa no Prêmio CAPES de Tese 2011. 
Neste trabalho, discutimos o papel da autoajuda para a construção da hegemonia analisando o caráter ideológico nesse discurso na formação de um trabalhador de novo tipo. Para tanto, estudamos o discurso de autoajuda voltado ao trabalho em três momentos distintos: sua gênese, no século XIX, sob os impactos da revolução industrial; na primeira metade do século XX, com o fordismo; e nas décadas finais do século XX e alvorecer do XXI. Identificamos os traços característicos do trabalhador demandado pelo capitalismo nesses períodos históricos e as estratégias de divulgação e construção de tais características por meio dos discursos de autoajuda. Procuramos evidenciar que esse processo ocorreu por fora e também por dentro da escola, discutindo a incorporação dos princípios de autoajuda nos relatórios de educação de Faure et al. (1972) e Delors (1996), patrocinados pela Organização das Nações Unidas para a Educação, a Ciência e a Cultura (UNESCO) e difundidos mundialmente para reformar a educação.

Visando analisar o fenômeno de rápida disseminação da autoajuda, resgatamos a noção gramsciana de ideologia, importante para se entender que sua finalidade é "modificar a opinião média de uma determinada sociedade [...] introduzindo 'novos lugares-comuns"' (Gramsci, 2004, p. 208). Recordamos aqui a afirmação de Marx sobre "'a solidez das crenças populares' que se expressam no senso comum, [sendo] aprofundada e atualizada a partir de novas condições históricas, na medida em que tais crenças podem ser transformadas em um novo senso comum, ou seja, no "bom senso"' (Simionatto, 2004, p. 81). Com base nos pressupostos de Marx, de que uma "persuasão popular tem, na maioria dos casos, a mesma energia de uma força material”, Gramsci (1984, p. 63) reforça a ideia de bloco histórico argumentando que

as forças materiais são o conteúdo e as ideologias são a forma - sendo que esta distinção entre forma e conteúdo é puramente didática, já que as forças materiais não seriam historicamente concebíveis sem forma e as ideologias seriam fantasias individuais sem as forças materiais.

A ideologia concebida como forma de determinado conteúdo desempenha uma função ordenadora na sociedade. Essa função concretiza-se na difusão de discursos explicativos e ordenadores de ações individuais. Tal processo exige um trabalho didático-formativo materializado numa linguagem veiculada também nas publicações de autoajuda, evidenciando uma construção paciente e sistemática voltada aos trabalhadores de empresas, aos "homens de negócios" que, em sua maioria, ocupam posições mais estratégicas nesses espaços. A elaboração desse tipo de discurso não se destina a trabalhadores analfabetos ou com pouca escolarização, mas que de alguma maneira acabam sendo atingidos.

Interpretando o conjunto de materiais analisados como prescrições que oferecem substrato para o exercício de ações de cunho eminentemente individualista, entende-se o discurso de autoajuda como um dos mecanismos que serve às demandas do capital na medida em que contribui para moldar o tipo de trabalhador necessário para atendê-las. Dissemina-se a ideia de que cabe ao indivíduo desenvolver ações para sua inserção e permanência no mercado de trabalho. Educa-se para o 
desenvolvimento de uma participação cívica, um dos valores da nova sociabilidade forjada pelo neoliberalismo.

Em cada um dos períodos analisados, esse discurso estabelece conexões entre os modos de pensar, sentir e agir para formar um trabalhador de novo tipo.

A adesão ou não de massas a uma ideologia constitui um exercício permanente de luta pela hegemonia de determinada classe social em que se busca instituir modos de pensar que correspondam às exigências de um período histórico. Nesse sentido, Rummert (2000, p. 37) destaca que

a disputa pela hegemonia passa, necessariamente, pela elaboração, articulação e difusão de discursos capazes de ordenar aspirações, sonhos, fantasias projetivas, valores já consolidados, necessidades materiais e simbólicas e projetos coletivos em que os indivíduos se percebam contemplados.

A elaboração de discursos, na acepção da autora, "em suas variações destinadas às diferenciadas frações de classe, é fundamentalmente pautada pelo projeto hegemônico, o qual desenha sua matriz e incorpora, de forma desarticulada e ressignificada, os elementos dos discursos opositores" (idem, ibidem). Sendo assim, temos um permanente exercício da hegemonia, por meio "de uma multiplicidade de formas e mediações" (idem, p. 26). Cumpre lembrar a observação gramsciana de que "a hegemonia [deve ser] entendida não apenas como direção política, mas também como direção moral, cultural e ideológica” (Gruppi, 1978, p. 11).

Ao analisar a hegemonia no padrão de acumulação fordista, ${ }^{1}$ Gramsci (2004), em "Americanismo e fordismo", sintetiza a expressão de uma racionalidade do trabalho na forma mais desenvolvida do capital. $\mathrm{O}$ trabalho industrial moderno converte-se no princípio educativo, no elemento integrador entre cultura e ciência. Portanto, o "americanismo" tem um caráter histórico,

representando o desenvolvimento de condições reais a uma nova civilização por exigir do homem um conhecimento de novo tipo, no qual a teoria e a prática se conformam numa unidade fazendo emergir uma possibilidade de um novo humanismo, de um novo tipo de relação entre teoria e prática, entre conhecimento e trabalho, mesmo que essas condições não tenham sido ainda exploradas. (Souza, 2002, p. 63)

É nesse sentido que o processo de conquista e manutenção da hegemonia pressupõe a difusão de uma determinada concepção de mundo (Rummert, 2000) que se dá por meio de mediações, com a construção de discursos e de uma linguagem que orienta certos modos de ver a realidade e de agir sobre ela. Para efetivar tais modos de apreender a realidade e agir, são produzidos "discursos explicativos

1 De acordo com Jesus (1998, p. 43), o "modo de produção de cada sistema social é muito importante para um processo educativo ser elaborado, assim como os fatores sociais, políticos e culturais também o são". 
sobre a realidade que, apesar de suas variações, designam, a partir de um padrão comum de referências, problemas, objetivos e valores de diferentes frações das classes dominadas" (idem, p. 36).

Com essa perspectiva teórica, investigamos o caráter ideológico do discurso de autoajuda na formação de um trabalhador de novo tipo, tendo em vista explicar o papel desse discurso para tornar hegemônico um projeto de sociabilidade do capital.

\section{PRESSUPOSTOS TEÓRICO-METODOLÓGICOS PARA ANÁLISE DOS DISCURSOS DE AUTOAJUDA}

Para realizar a análise dos livros de autoajuda, recorremos às contribuições de Fairclough (2001) que relacionam discurso com mudança social, com a construção de sistemas de conhecimento e crenças, permitindo discutir as ideologias embutidas nas práticas discursivas que, de tão repetidas, acabam se tornando parte de uma linguagem do senso comum. Segundo o autor, "as ideologias embutidas nas práticas discursivas são muito mais eficazes quando se tornam naturalizadas e atingem os status de 'senso comum" (Fairclough, 2001, p. 117). "Embora seja verdade que as formas e o conteúdo dos textos trazem o carimbo (são traços) dos processos e das estruturas ideológicas, não é possível 'ler' a ideologia nos textos" (idem, p. 118).

A difusão de um modo de pensar homogêneo visado pelo discurso de autoajuda decorre em grande parte da repetição ad nauseam das palavras. Esse discurso incita o engajamento dos trabalhadores numa perspectiva tridimensional: como texto, como uma prática social e como prática discursiva. Para Fairclough, o discurso tem efeito porque mobiliza, conduz o indivíduo a algum tipo de ação. Sendo assim, analisamos o discurso de autoajuda como aquele que difunde uma concepção de mundo e de homem e também como modos de ação no mundo, pautada em um conjunto de valores "pretensamente" universais e indispensáveis à nova gestão do trabalho em tempos de neoliberalismo, de modo que constrói um ideal de trabalhador.

As indicações metodológicas de Fairclough (2001) orientaram a análise de discurso das obras de autoajuda indicadas a seguir, selecionadas pela enorme repercussão que tiveram em diferentes momentos históricos.

Quadro 1- Livros de autoajuda selecionados para análise

\begin{tabular}{l|l|l|l}
\hline \multicolumn{1}{c|}{ Título } & \multicolumn{1}{c|}{ Autor } & \multicolumn{1}{c}{$1^{\text {a } \text { Edição }}$} & \multicolumn{1}{c}{ País } \\
\hline Ajuda-te (self-help) & Samuel Smiles & 1859 & Inglaterra \\
\hline O caráter & Samuel Smiles & 1871 & Inglaterra \\
\hline $\begin{array}{l}\text { O dever: coragem, paciência } \\
\text { e resignação }\end{array}$ & Samuel Smiles & 1880 & Inglaterra \\
\hline Vida e trabalho & Samuel Smiles & 1887 & Inglaterra \\
\hline Como fazer amigos e influenciar pessoas & Dale Carnegie & 1936 & Estados Unidos \\
\hline
\end{tabular}

(continua...) 
(...continuação)

\begin{tabular}{l|l|l|l}
\hline \multicolumn{1}{c|}{ Título } & \multicolumn{1}{c|}{ Autor } & \multicolumn{1}{c}{$1^{\text {a } \text { Edição }}$} & \multicolumn{1}{c}{ País } \\
\hline $\begin{array}{l}\text { Como falar em público e influenciar } \\
\text { pessoas no mundo dos negócios }\end{array}$ & Dale Carnegie & 1981 & Estados Unidos \\
\hline Empregabilidade: o caminho das pedras & $\begin{array}{l}\text { José Augusto } \\
\text { Minarelli }\end{array}$ & 1995 & Brasil \\
\hline Quem mexeu no meu queijo? & Spencer Johnson & 1998 & Estados Unidos \\
\hline Você: a alma do negócio & $\begin{array}{l}\text { Roberto } \\
\text { Shinyashiki }\end{array}$ & 2001 & Brasil \\
\hline
\end{tabular}

Fonte: Banco de dados da pesquisa.

Elaboração das autoras.

Além desses livros, o corpus documental analisado abrangeu dois relatórios da UNESCO: Relatório da Comissão Internacional sobre o Desenvolvimento da Educação (1972), coordenado por Edgar Faure, e o Relatório da Comissão Internacional sobre Educação para o século XXI (1996), coordenado por Jacques Delors.

Constatamos que princípios, valores, comportamentos, condutas e visões de mundo disseminados pela literatura de autoajuda estavam presentes nas diretrizes e reformas educacionais contemporâneas. Tais evidências possibilitaram pensar que os discursos da UNESCO que atribuíram prioridade ao "aprender a ser" funcionavam de maneira semelhante e complementar aos de autoajuda, valendo-se das estratégias de persuasão para produzir uma nova sociabilidade demandada pelo capital. Com essa perspectiva, analisamos os relatórios de Faure et al. (1972) e Delors (1996) procurando demonstrar que essa estratégia da nova pedagogia da hegemonia se desenvolvia por fora, mas também por dentro do sistema educacional.

\section{“AJUDA-TE E DEUS TE AJUDARÁ". A AUTOAJUDA DE SMILES}

A ampla popularização das ideias de Smiles, pai da autoajuda para trabalhadores, possibilita compreendermos o discurso de autoajuda do século XIX constituído e constituinte do ideário positivista que priorizava a ordem e o progresso, a valorização do trabalho livre, perseverante, árduo, dedicado, concepção amplamente frisada por Smiles nas publicações analisadas.

Sua influência atingiu a intelectualidade brasileira no fim do século XIX e início do século XX, "no imperialismo liberal burguês inglês, 'com o poder de universalizar os particularismos associados a uma tradição histórica singular', isto é, transpor ideias de uma realidade de capitalismo industrial, para uma sociedade escravocrata agrária-exportadora” (Bastos, 2000, p. 132). Isso se deve ao fato de as ideias aparecerem desistoricizadas, como resultado "da neutralização do contexto histórico que resulta da circulação internacional dos textos e do esquecimento correlato das condições de origem [...]" (Bourdieu; Wacquant, 1999, p. 32).

Smiles apostou no efeito dos excertos biográficos, nos exemplos edificantes, de sucesso, no princípio da evidência de "boas ações", "boas práticas" que, uma vez 
generalizadas, legitimariam as perspectivas de autorrealização, possibilidade de projeção e ascensão social. Em vista disso, em sua estratégia discursiva, empecilhos e fracassos são desconsiderados. "A carreira é tão rápida que não tolera que nos detenhamos a informar-nos daqueles que caíram prostrados no caminho" (Smiles, 1910, p. 78). Desse modo, o discurso de Smiles constitui-se num "discurso da prática" que, para ser aceito, associa-se a outras estratégias discursivas de maneira que possa convencer e converter os leitores trabalhadores.

A propalação da autoajuda de Smiles dá-se também pela profusão massiva de provérbios ou máximas, outro mecanismo linguístico de difusão de ideias. "Ajuda-te e Deus te ajudará" é o provérbio basilar da autoajuda smilesiana. Pelas dezenas de provérbios recorrentes em seus livros, apreendemos as concepções de trabalho, de homem e sociedade/mundo disseminadas por Smiles.

Smiles concentrou seus esforços na perspectiva de uma instrução popular, escrevendo livros, participando de palestras e afirmando um caráter moralizante, a fim de fortalecer um ideal de autoajuda como um caminho para a reforma da sociedade, externando valores morais e deveres voltados a uma ética do trabalho. Outro traço marcante na literatura de Smiles é o uso de fábulas, recurso metodológico utilizado para respaldar de modo operatório as prescrições do autor. A divulgação das premissas de Smiles

traduz um espírito de época, [em que] o trabalho se naturaliza, a partir do que se mostrava como um senso comum universal, preparando o espírito da elite ilustrada brasileira, para a ideologia do sucesso individual, como fruto da persistência, do esforço e do trabalho [...]. (Bastos, 2000, p. 133)

\section{“COMO INFLUENCIAR PESSOAS?” A AUTOAJUDA DE CARNEGIE}

O discurso de autoajuda nas primeiras décadas do século XX foi produzido em meio a um contexto de crise, guerra e demandas de produção, sendo associado ao consumo prudente e racional para corresponder às necessidades e expectativas das empresas. Foi um período com expressiva ascensão e projeção dos "homens de negócios", público-alvo tanto dos escritos de Henry Ford quanto da literatura de autoajuda de Carnegie.

O discurso de autoajuda, naquele contexto, difundia a crença no potencial humano para articular uma ordem social democrática. Sendo assim, mais significativa do que qualquer aprendizagem era a solução habilidosa dos problemas, discurso este extremamente adequado à forma de organização de trabalho taylorista-fordista predominante. Enfatizava o saber-fazer e o aprender-fazendo na formação prática do cidadão produtivo via administração do trabalho racionalizado.

A autoajuda do início do século XX respaldava não apenas visões normativas sobre o que se devia e não se devia fazer, mas suas prescrições visavam direcionar esse fazer à eficácia e produtividade no trabalho. $\mathrm{O}$ trabalhador idealizado por essa literatura e almejado para o trabalho no século XX era produtivo, obediente, 
disciplinado, abstêmio, monogâmico, adaptável, hábil e dócil. Em suma, um operário (con)formado.

O discurso de autoajuda destinava-se aos "homens de negócios" e promoveria uma mudança individual e desenvolveria neles a capacidade de influenciar e converter os trabalhadores a um determinado modo de pensar. Nesse sentido, Carnegie, um dos mais expressivos autores de autoajuda daquele período, aposta no valor educativo dos exemplos. Esses constituem uma estratégia eficaz de aprendizagem, educando para a ação, para a mudança de conduta, permitindo desenvolver a serenidade para aceitar as coisas que não se podem modificar. É interessante observar o caráter contraditório dos exemplos que ao mesmo tempo incitam à ação e produzem a conformação.

Visando influenciar e convencer tanto o público leitor quanto os participantes de cursos, Carnegie utiliza de maneira expressiva frases de efeito e verbos no modo imperativo, elementos marcantes em seus livros que objetivam dar suporte para que o leitor se sinta forte, seguro, incline-se a exercer o seu poder de persuasão visando convencer ou, nas palavras do autor, "impressionar".

A autoajuda de Carnegie aproxima-se de um discurso religioso, já que "o alívio e a paz se encontram na religião e na prece”(Carnegie, 1994, p. 204). O autor usa parábolas bíblicas, como a do bom samaritano, e vale-se das técnicas de oratória. Mescla à religião o apelo ao poder do pensamento positivo: "use em seu trabalho as técnicas da linguagem positiva" (Carnegie, 2006, p. 210). Segundo o autor, negócios, vida social e satisfações pessoais dependem, grandemente, da capacidade de se comunicar, por isso dedica a primeira parte de seu livro intitulado Como fazer amigos e influenciar pessoas aos fundamentos da oratória positiva.

A autoajuda de Dale Carnegie se populariza em um momento de crise, apresentando-se como discurso orientador de conduta, ensinando a arte de persuadir para influenciar mudanças de pensamento e de comportamento.

\section{“SEJA SEU PRÓPRIO EMPRESÁRIO”. A AUTOAJUDA DE MINARELLI}

Quase um século depois, já na virada para o século XXI, a autoajuda de Minarelli prepara um terreno fértil para a proliferação de determinado modo de pensar o desemprego, com base em uma conotação eminentemente positiva, por isso a ênfase na empregabilidade entendida como a capacidade individual de gerar trabalho e renda.

É um discurso que pretende ocultar as determinações econômicas, políticas e sociais que viabilizam as formas de exploração e dominação para a reprodução do capital. Essa simplificação da linguagem, do vocabulário relativo ao desemprego é particularmente revelada pelo uso de eufemismos alegando que ser um desempregado na atualidade significa, tão e simplesmente: estar disponível; ter o tempo a seu favor; ter a oportunidade de alinhar o trabalho com sua vocação; ter a possibilidade de solucionar problemas e estar à disposição do mercado; ser seu próprio empresário ou promoter (Minarelli, 1995). Ademais, recomenda o autor, quando "o emprego 
sai de cena" o desempregado deve estar à disposição do mercado para ajudar o tomador de serviços. Tal discurso é expressão da "nova pedagogia da hegemonia", contribuindo para que

o exercício da dominação de classe seja viabilizado por meio de processos educativos positivos. Sua efetividade justifica-se em parte pela força de sua fundamentação teórica, que legitima iniciativas políticas de organizações e pessoas baseadas na compreensão de que o aparelho de Estado não pode estar presente todo o tempo e espaço e que é necessário que a sociedade civil e que cada cidadão se tornem responsáveis pela mudança da política e pela definição de formas alternativas de ação social. (Martins et al., 2010, p. 24)

Trata-se, assim, de um discurso criador e propagador de "verdades" que imputam ao indivíduo a responsabilidade pelas condições adversas do mercado de trabalho. Para a consolidação desse discurso, Minarelli utiliza estratégias como o eufemismo, metaforiza os exemplos, os modelos de sucesso. Os exemplos, os excertos biográficos permitem ao autor condensar em seu relato os princípios que deseja demarcar; como assinalava Smiles (1893, p. 5), os exemplos "produzem bons efeitos". O uso de modelos de sucesso busca modificar comportamentos, de tal forma que, associadas aos fragmentos de histórias de vida, atitudes como coragem, paciência, força de vontade, autodisciplina, automotivação, entre outras, são utilizadas num contexto em que a síntese é a moral da história.

$\mathrm{Na}$ construção discursiva de Minarelli estão presentes flexões verbais no modo imperativo. O uso do imperativo na construção do discurso de autoajuda manifesta ordem, apelo à concretização de uma ação, remetendo sempre ao uso afirmativo do conteúdo exposto. Assim, "desenvolva habilidades [...] procure clientes [...] tema ser superado e descartado [...] não fique parado [...] precisa adequar-se [...]" (Minarelli, 1995, p. 41-59). As demandas expressas no discurso de Minarelli não são questões meramente semânticas, mas visam a recomendações, receitas sobre o que fazer e como fazer para tornar-se um trabalhador de novo tipo. A ideia de produção de um indivíduo fiel, dedicado, honesto, competente, idôneo, responsável, com posicionamento, pensamentos positivos e iniciativa está associada à noção de mudança, em especial à mudança de posicionamento perante a situação de emprego e desemprego. Significa dizer que a cada um dos leitores está delegada a responsabilidade de criar seu networking, examinar, decidir, corrigir o roteiro de sua carreira, adequar-se aos padrões, competir no mercado, saber vender bem os seus serviços (idem) e, em caso de fracasso, deve entender que fez as escolhas erradas e assumir os ônus.

O discurso de autoajuda de Minarelli visa particularizar a situação do desemprego, estimulando os indivíduos a desenvolverem sua empregabilidade como uma arma individual, desencorajando as formas coletivas de luta e reivindicação, buscando-se, assim, a reprodução da ordem estabelecida. 


\section{"APENAS OS MELHORES ATINGIRÃO SUAS METAS". A AUTOAJUDA DE SHINYASHIKI}

O discurso de autoajuda de Shinyashiki, em sintonia com a sociabilidade necessária ao trabalho flexível, difunde ideias no "sentido de garantir a adaptação dos novos homens às instáveis condições sociais e profissionais que marcam o início desse milênio [...]" (Falleiros; Pronko; Oliveira, 2010, p. 93). O indivíduo é convidado a gerir riscos considerando que os "empregos mudaram de lugar" e "a estabilidade não existe mais” (Shinyashiki, 2001, p. 28).

As recomendações do autor, médico psiquiatra, difundem uma concepção de mundo em mudança, de incertezas, hipercompetitivo, instável, cenário que utiliza para afirmar que o indivíduo precisa assumir o controle da situação. Assim, reforça a ideologia dominante e a crença enganosa de que a solução de problemas está apenas no próprio indivíduo, desconsiderando as determinações econômicas, sociais, históricas e políticas que envolvem a produção da existência. O discurso de Shinyashiki culpa o leitor por sua condição social, promovendo um corte com o social e com o outro, alegando que no indivíduo residem as respostas e as soluções, pois a responsabilização individual transforma sonho e oportunidades em resultados (idem).

O discurso desse autor também possui um "tom" religioso. A vida nos devolve o resultado de nossa competência como prêmio, bênção. Na mesma perspectiva de Smiles, enfatiza o valor educativo das dificuldades, da dor, do sofrimento, necessários ao crescimento profissional. Tarefas são missões. Nesse sentido, a exemplo de Minarelli, o uso de eufemismos também é uma constante nas recomendações apregoadas pelo autor. Os problemas, as derrotas ganham conotação positiva e são vistos como uma oportunidade de aprendizado. Por esse ponto de vista, o conflito nada mais é do que o resultado da dificuldade de ver e analisar pelo ponto de vista do outro. Quem cria conflito é considerado rígido, inflexível, e, conforme o autor, a rigidez leva ao radicalismo (idem).

Essas ideias são reiteradas nas frases de efeitos que caracterizam o discurso de Shinyashiki, sendo utilizadas como síntese, como a essência a ser retida pelo leitor. Pode ser considerada uma estratégia para simplificar e popularizar o discurso que pretende "ensinar a ser".

O uso de metáforas é providencial ao discurso de Shinyashiki. Elas funcionam como um elo de proximidade com o leitor. Em Você: a alma do negócio, o profissional é um atleta que decide se quer ser campeão ou perdedor. Um campeão não se acomoda, quer voar mais alto, adora a vitória, adora participar das finais dos campeonatos, lidando com toda a cobrança e pressão, é um guerreiro. Além disso, numa linguagem persuasiva, frases e verbos no imperativo são utilizados abundantemente, visando induzir o pensamento positivo com estímulo à ação, uma vez que para o autor a "passividade mata". Assim, o autor ordena: pare de esperar que alguém the diga o que fazer; assuma que você é a alma do negócio; pare de reclamar do governo; seja a melhor solução; venda primeiro a sua imagem; valorize seus sentimentos, sua intuição (idem). 
De outro modo, o discurso do autor também opera por associações: os fracos buscam seus direitos; os bons fazem seus deveres, e os sensacionais procuram mostrar que são imprescindíveis; os sábios conseguem compreender com os olhos do coração. Por meio dessa estratégia, Shinyashiki força o indivíduo a pensar sobre a posição que deseja assumir no mercado de trabalho. Diante do cardápio de opções, o leitor provavelmente não iria optar nem pelo fraco, nem pelo bom. Quem não quer ser "sensacional" ou "sábio"? Mas apenas os melhores atingirão suas metas. Quem se mantém como está, ficará para trás (idem).

O caráter dinâmico das recomendações da literatura de autoajuda de Shinyashiki também reside no manejo de exemplos que visam confirmar as assertivas do autor. É necessário ressaltarmos que os exemplos constituem uma estratégia pedagógica recorrente de que se valem os autores desse gênero literário. Retratam e disseminam modos de ser e agir reprisados em histórias de sucesso, modelos ideais; querem convencer a respeito do valor das "soluções pessoais" (Martelli, 2006).

Shinyashiki é um autor que intercala dois discursos: o que postula ação, mudança de atitude, responsabilizando os indivíduos por suas escolhas, alertando que vencem apenas os melhores; o outro discurso é reconfortante, fala das oportunidades de todos, de ter personalidade, além de habilidades para ser empreendedor, ou para reconhecer suas limitações e desenvolver determinadas atitudes para ser empregado.

Para isso, Shinyashiki propõe em seu discurso soluções, receitas eminentemente práticas, afinal postula: a solução está dentro de você; a decisão sobre suas escolhas é somente sua; você tem a força para superar, basta ter coragem, se não tiver, será visto como covarde e imaturo. Precisa ser ousado, empreendedor, analisar as chances de sucesso, desenvolver a capacidade para trabalhar muito, mas com criatividade e amor ao próximo (Shinyashiki, 2001).

Assim, o objetivo de Shinyashiki (2001, p. 24) é "fazer mudanças na maneira de pensar e de trabalhar" do indivíduo. Como diria Gramsci (2004, p. 207), "as modificações nos modos de pensar, nas crenças, nas opiniões, não ocorrem, mediante 'explosões' rápidas, simultâneas e generalizadas, mas sim, quase sempre, através de 'combinações sucessivas', de acordo com 'fórmulas de autoridade' variadíssimas e incontroláveis".

\section{“QUEM NÃO MUDAR, MORRERÁ!” A AUTOAJUDA DE JOHNSON}

Sennett (2006, p. 168) afirma que, sob a égide da mudança, "as pessoas [...] precisam é de uma âncora mental e emocional; precisam de valores que as ajudem a entender se as mudanças no trabalho [...] valem a pena”. É nesse sentido que se pode apreender o discurso de Johnson. Um discurso que contribui para a promoção desses valores, que institui modos de viver e comportar-se no trabalho, reforçando as teses da adaptação, adequação, aceitação e mudança. Enfim, dissemina uma concepção de mundo e trabalho cuja essência é a "adaptação à mudança". Associada ao vocábulo da mudança, Johnson utiliza a flexibilidade, palavra de ordem para o sucesso profissional do alvorecer do século XXI. 
Nessa linha de pensamento, o autor apresenta suas concepções de mundo e trabalho contando a história de ratos em busca de um novo queijo. Cria uma situação que remete à necessidade de uma revisão de valores como elementos para lidar com o inesperado, o que exige um novo modo de pensar, sentir e agir para enfrentar desafios, pensar sobre os erros, rever obstáculos que estão dentro de cada um. A adaptação, no discurso do autor, representa nada mais que a recompensa à adesão ao novo modo de pensar, sentir e agir diante de mudanças. Johnson faz uso abundante de frases de efeito que são estrategicamente posicionadas no texto como síntese daquilo que deve ser apreendido da leitura. Reforçando a moral da história, frases de efeito são apresentadas dentro de uma fatia de queijo ilustrada. $\mathrm{O}$ recurso visual é um importante mecanismo utilizado para comunicar a ideia e buscar adesão aos preceitos da autoajuda.

Dessa maneira, em seu discurso o autor estabelece leis da mudança e adaptação. Essas leis são expressas por meio de uma infinita repetição de palavras, um dos recursos linguísticos utilizados pelo autor como artifício para prender a atenção e persuadir os leitores. $\mathrm{O}$ reforço à repetição é uma estratégia discursiva comum na literatura de autoajuda e, no caso de Johnson, as palavras mais frisadas são: mudança; adaptação; flexível; bem-sucedidos; comportamento; sucesso; imaginação; medo (Johnson, 2001).

A autoajuda de Johnson visa educar também pelo uso de metáforas. É criada uma perspectiva de interação entre a metáfora e o indivíduo, nutrindo-o para ser capaz de realizar e resolver seus problemas. Johnson faz um jogo interessante em seu discurso. No diálogo do grupo de amigos, acrescenta exemplos práticos de situações ocorridas no trabalho, reforçando assim as leis da adaptação às mudanças criadas pelo autor. Mudar atitudes significa enxergar a mudança como importante, sobretudo mantendo o senso de humor, pois "quem não mudar, morrerá!" (idem).

Constatamos que, além dos livros de autoajuda, muitas dessas ideias eram disseminadas pela mídia e haviam penetrado o discurso educacional. Analisamos, então, dois relatórios da UNESCO selecionados pela prioridade atribuída ao "aprender a ser".

\section{UNESCO “ENSINA A SER”}

Os dois documentos da UNESCO analisados apresentam propostas para reformar a educação, prioridades e valores baseados em determinadas concepções de mundo, de trabalho e de educação presentes nos Relatórios Faure (1972) e Delors (1996), como ficaram conhecidos os referidos trabalhos. A leitura de ambos possibilita constatar a transformação de conceitos sofisticados em um manual prescritivo para a educação para o século XXI. Para a UNESCO, adquirir conhecimentos não é suficiente para a atuação profissional, é preciso transpô-los para a vida produtiva e social. Nessa perspectiva, à semelhança dos manuais de autoajuda que difundem ideias, propalam exaustivamente jeitos de ser no trabalho. Os referidos relatórios também se dedicam a "ensinar a ser" delineando traços, atributos necessários à 
formação do trabalhador ideal à reprodução do capital. Com base na análise de Falleiros (2005, p. 211), pode-se pensar que a "proposta educacional" dos relatórios tem como intuito

conformar o "novo homem" de acordo com os pressupostos técnicos, psicológicos, emocionais, morais e ético-políticos da flexibilização do trabalho e como um modelo de cidadania que não interfira nas relações burguesas fundamentais no contexto da ampliação da participação política.

O discurso configurado no Relatório Faure (1972) apresenta o diagnóstico de um mundo e de uma educação em crise e anuncia a necessidade da construção de uma nova concepção de mundo, do preparo de um novo homem para atuar num contexto de transformação produtiva. Dessa forma, difunde estratégias educacionais, conteúdos, habilidades e valores necessários ao modelo de sociabilidade capitalista da década de 1970, alegando ser preciso reformar, adequar os sistemas de ensino para a inserção do trabalhador no mundo do trabalho marcado por inovações tecnológicas. Enaltecendo a tecnologia, exige um novo modo de conceber a educação, propondo a revisão radical dos sistemas educativos e o esforço de solidariedade, da apropriação e assimilação da ideia do novo.

Esse modo de ver a educação prioriza o "aprender a ser", alegando a urgência em se formar um novo homem focado no desenvolvimento de uma educação permanente. Encontra-se aí o germe do slogan "educação ao longo da vida". A necessidade de (con)formação desse homem de novo tipo é destacada como "objetivo comum a todos os sistemas de educação". A educação para formar esse homem terá de ser global e permanente. Sem dúvida, está se falando de uma educação de novo tipo capaz de imprimir forte caráter individualista e flexível, cuja reforma educacional poderia corrigir a fragilidade de certas formas de instrução, alargando as funções do autodidatismo e aumentando o valor das atitudes ativas e conscientes de aquisição de conhecimentos (Faure, 1972). Nessa perspectiva, o conhecimento que está em constante evolução reforça a necessidade do "aprender a ser", o que ajudaria cada indivíduo a alargar suas faculdades pessoais, a "liberar sua força criadora".

Os autores dos relatórios arrebanharam muitos adeptos, alegando que essa força criadora está relacionada à vocação pessoal de cada um, caminho que favoreceria a mobilidade social e igualaria as oportunidades.

Também analisamos no Relatório Delors (1996) as recomendações para “aprender a ser", soluções propostas, histórias contadas, metáforas apresentadas, palavras, conceitos e concepções enfatizados para direcionar a formação do indivíduo desejável para o século XXI. Seus elaboradores prescrevem uma educação que atenda à formação de um trabalhador de novo tipo eficiente, proativo, flexível e funcional, solidário, que tolere e conviva com as diferenças espirituais e culturais. Diante disso, estimulam a iniciativa, o trabalho em equipe, as "sinergias realistas", tendo em conta os recursos locais, o autoemprego e o espírito empreendedor. Afirmam que é preciso educar para a superação de si mesmo, para a responsabilização e necessidade de participação de cada um, para o desenvolvimento de virtudes cívicas. 
É reiterada a importância de estimular o indivíduo "a tomar nas mãos o seu próprio destino" e da formação para tornar o indivíduo capaz de evoluir, de se adaptar a um mundo em rápida mudança e capaz de dominar essas transformações. Para responder às exigências desse mundo, seria então necessário desenvolver nesse homem: espírito de iniciativa, criatividade, abertura à mudança, o sentido das responsabilidades, comportamento inovador e proativo, espírito de adaptação, aptidão para se comunicar, flexibilidade, mantendo, além disso, cooperação ativa. O Relatório Delors busca a modernização de mentalidades, a construção de uma cultura pessoal, a autonomia individual, o discernimento, o gosto pelo trabalho em equipe, de tornar o indivíduo agente de mudança capaz de resolver problemas, negociar com paz e sem o uso da força (Delors, 1996).

Os relatórios Faure e Delors, à semelhança da literatura de autoajuda, alimentam a ideologia da instrumentalidade, da adaptação e do consenso. De que maneira? Difundindo exemplos edificantes, expressivos, modelos de sucesso, figuras notáveis que superaram as adversidades de modo que conquistaram ascensão social e inserção no mercado de trabalho.

A literatura de autoajuda "ensina a ser" por fora da escola, mas os relatórios da UNESCO trazem esse discurso para dentro dela, influenciando currículos, a formação de professores, a organização escolar e a gestão educacional com discurso e ações que visam reformar a educação do século XXI, atribuindo à instituição escolar a "tarefa de ensinar as futuras gerações a exercer uma cidadania 'de qualidade nova', a partir da qual o espírito de competitividade seja desenvolvido em paralelo ao espírito da solidariedade, por intermédio do abandono da perspectiva de classe" (Falleiros, 2005, p. 211).

A análise da atuação das comissões da UNESCO possibilita que estas sejam interpretadas como intelectuais orgânicos do capital visando conformar a força de trabalho não só em seus aspectos técnicos, mas fundamentalmente nos atitudinais, com o objetivo de criar disposições internas, moldar subjetividades, ensinando a ser.

\section{CONCLUSÕES}

Neste trabalho foram analisadas as concepções de mundo, trabalho e educação encontradas nos clássicos da autoajuda e presentes também nos documentos da UNESCO para a educação, explicitando sua convergência aos preceitos e demandas capitalistas.

A autoajuda, desde o século XIX, vem consolidando-se com um veículo da ideologia, difundindo uma forma de interpretar a realidade adequada aos padrões de sociabilidade necessários ao capital. Desse modo, se a "eficácia das ideologias decorre da sua capacidade de interferir na vida concreta das classes, dos homens" (Dias, 2006, p. 74), as formulações da autoajuda para as relações de trabalho têm servido, ao longo de séculos, para oferecer, à classe trabalhadora, a compreensão das questões sociais como problemas pessoais. 
Constatamos semelhanças entre o discurso difundido nos relatórios da UNESCO e nos de autoajuda. A noção de mudança de comportamento, de atitudes, das formas de ver e agir no mundo constitui elemento central tanto na literatura de autoajuda como nos Relatórios Faure e Delors. Esses relatórios que "ensinam a ser" são difundidos mundialmente para orientar as reformas educacionais, atribuindo à educação a responsabilidade exclusiva pela situação social dos indivíduos. Os argumentos em favor da modificação de mentalidade, de comportamento e de atitudes visam moldar para a empregabilidade, para o empreendedorismo e para a conformação ao desemprego. Os princípios para "aprender a ser" esse novo trabalhador, segundo a ótica da autoajuda e da UNESCO, estão explicitados nos seguintes atributos: perseverança, coragem, criatividade, capacidade para inovar, flexibilidade, pensamento positivo, disciplina, caráter, paciência, economia, entre outros.

Entendida como uma das estratégias da nova pedagogia da hegemonia (Neves, 2005), a autoajuda produz efeito à medida que faz chegar ao povo determinadas concepções de mundo. Nesse sentido, podemos considerar os "charlatões ideológicos" (Petras, 2007) como organizadores e persuasores permanentes, contribuindo para "manter ou para modificar uma concepção de mundo, isto é, para suscitar novas maneiras de pensar" (Gramsci, 2004, p. 53).

Procuramos evidenciar que, apesar das mutações, o discurso de autoajuda caracteriza-se por um interesse permanente que atravessa os diferentes períodos estudados: a construção do consenso em torno da concepção burguesa de mundo. Diante de tantas mudanças, aquele se manteve na autoajuda desde o início do século XIX, contribuindo para a contenção da classe trabalhadora, oferecendo histórias personalizadas com vistas a ocultar as contradições e minar a consciência de classe.

De acordo com Gramsci (idem, p. 246), há duas perspectivas pelas quais se podem considerar os leitores: “[...] como elementos ideológicos, 'transformáveis' filosoficamente, capazes, dúcteis, maleáveis à transformação; [...] como elementos 'econômicos', capazes de adquirir as publicações e de fazê-las adquirir por outros". Em contrapartida, se há resistências e os indivíduos não são tão dúcteis assim, é preciso reconhecer que o capital apresenta-se mais organizado, mais orgânico, mobilizado, consistente (Rummert, 2000).

Os recordes de vendas da literatura de autoajuda e a rápida propagação do ideário da UNESCO nos permitem estimar a abrangência desse projeto que "ensina a ser" na perspectiva do capital e do desafio de desconstruí-lo rumo a outro projeto histórico, no qual a razão do ensinar e aprender seja a formação do ser social pleno e emancipado.

\section{REFERÊNCIAS}

BAstos, Maria Helena Câmara. Leituras da ilustração brasileira: Samuel Smiles (1812-1904). Ícone, [s.1: s.n.], v. 6, n. 1, p. 117-134, 2000.

Bourdieu, Pierre; Wacquant, Löis. Sobre as artimanhas da razão imperialista. In: . Escritos de educação. Petrópolis: Vozes, 1999. p. 17-32. 
Carnegie, Dale. Como fazer amigos e influenciar pessoas. 45. ed. São Paulo: Editora Nacional, 1994.

Como falar em público e influenciar pessoas no mundo dos negócios. 45. ed. Rio de Janeiro: Record, 2006.

Delors, Jacques (Org.). Educação: um tesouro a descobrir. Relatório da Comissão Internacional sobre Educação para o século XXI. São Paulo: Cortez; Brasília, DF: MEC/UNESCO, 1996.

Dias, Edmundo Fernandes. Política brasileira: embate de projetos hegemônicos. São Paulo: Instituto José Luís e Rosa Sundermann, 2006.

Fairclough, Norman. Discurso e mudança social. Brasília: Editora Universidade de Brasília, 2001.

FAlleiros, Ialê. Parâmetros Curriculares Nacionais para a educação básica e a construção de uma nova cidadania. In: Neves, Lúcia Maria Wanderley (Org.). A nova pedagogia da hegemonia: estratégias do capital para educar o consenso. São Paulo: Xamã, 2005. p. 207-235.

. Pronko, Marcela Alejandra; Oliveira, Maria Teresa Cavalcanti de. Fundamentos históricos da formação/atuação dos intelectuais da nova pedagogia da hegemonia. In: Neves, Lúcia Maria Wandeley (Org.). Direita para o social e esquerda para o capital: intelectuais da nova pedagogia da hegemonia no Brasil. São Paulo: Xamã, 2010. p. 39-95.

Faure, Edgar; Her rera, Felipe; Kaddoura, Abdul-Razzak; Lopes, Henri; Petrovski, Arthur Vladimirovich; Rahnema, Majid; Ward, Frederick Champion. Aprender a ser: la educación del futuro. Relatório da Comissão Internacional sobre o Desenvolvimento da Educação. Madrid: Alianza Editorial/UNESCO, 1972.

Gramsci, Antonio. Concep̧ão dialética da história. 5. ed. Rio de Janeiro: Civilização Brasileira, 1984.

Cadernos do cárcere. 3. ed. Tradução Carlos Nelson Coutinho. Rio de Janeiro: Civilização Brasileira, 2004.v. 2.

GruppI, Luciano. O conceito de hegemonia em Gramsci. 4. ed. Rio de Janeiro: Graal, 1978. Jesus, Antônio Tavares de. O pensamento e a prática escolar em Gramsci. Campinas: Autores Associados, 1998.

Johnson, Spencer. Quem mexeu no meu queijo? 16. ed. Rio de Janeiro: Record, 2001.

Liker, Jeffrey. O modelo Toyota: 14 princípios de gestão do maior fabricante do mundo. Porto Alegre: Bookman, 2005.

Martelli, Carla Giani. Autoajuda e gestão de negócios: uma parceria de sucesso. Rio de Janeiro: Azougue, 2006.

Martins, André Silva; Oliveira, Daniela Motta de; Neves, Lúcia Maria Wanderley, Melo, Marcelo Paula de; Santos, Marco Antonio Carvalho. Fundamentos teóricos da formação/atuação dos intelectuais da nova pedagogia da hegemonia. In: Neves, Lúcia 
Maria Wanderley (Org.). Direita para o social e esquerda para o capital: intelectuais da nova pedagogia da hegemonia no Brasil. São Paulo: Xamã, 2010. p. 97-153.

Minarelli, José Augusto. Empregabilidade: o caminho das pedras. São Paulo: Gente, 1995.

Neves, Lúcia Maria Wanderley (Org.). A nova pedagogia da hegemonia: estratégias do capital para educar o consenso. São Paulo: Xamã, 2005.

Petras, James. Imperialismo e luta de classes no mundo contemporâneo. Florianópolis: Editora da UFSC, 2007.

Rummert, Sonia Maria. Educação e identidade dos trabalhadores: as concepções do capital e do trabalho. São Paulo: Xamã; Niterói: Intertexto, 2000.

Sennett, Richard. A cultura do novo capitalismo. Rio de Janeiro: Record, 2006.

Shinyashiki, Roberto. Você: a alma do negócio. São Paulo: Gente, 2001.

Simionatto, Ivete. Gramsci: sua teoria, incidência no Brasil, influência no serviço social. 3. ed. Florianópolis: Editora da UFSC; São Paulo: Cortez, 2004.

Smiles, Samuel. O caráter. São Paulo: Papelivros, s.d. . Ajuda-te (self-help). Rio de Janeiro: F. Briguiet \& CIA, 1893. . Vida e trabalho. Rio de Janeiro: Garnier, 1901. O dever: coragem, paciência e resignação. Rio de Janeiro: Garnier, 1910.

SouzA, José dos Santos. Trabalho, educação e sindicalismo no Brasil: anos 90. Campinas: Autores Associados, 2002.

\section{SOBRE AS AUTORAS}

Adriana Cláudia Turmina é doutora em educação pela Universidade Federal de Santa Catarina (UFSC). Membro da equipe de capacitação docente do Serviço Nacional de Aprendizagem Comercial (SENAC/SC).

E-mail: aturmina@hotmail.com

Eneida Oto Shiroma é doutora em educação pela Universidade Estadual de Campinas (UNICAMP). Professora da Universidade Federal de Santa Catarina (UFSC).

E-mail: eneida@ced.ufsc.br

Recebido em setembro de 2011 Aprovado em março de 2012 


\section{ADRIANA CLÁUDIA TURMINA E ENEIDA OTO SHIROMA}

"Se você não mudar, morrerá": a (con)formação de um trabalhador de novo tipo no discurso de autoajuda

Nesta pesquisa foi abordada a face ideológica do discurso de autoajuda na formação de um novo tipo de trabalhador, explicando o seu papel na construção da hegemonia. Estudamos os princípios desse discurso em três períodos: sua gênese, no 
século XIX, nas primeiras décadas do século XX e início do século XXI. Analisamos como os princípios de autoajuda foram reproduzidos no Relatório Delors e Faure. Com base em Gramsci e Fairclough, explicamos a autoajuda como um discurso ideológico presente nos relatorios da Organização das Nações Unidas para a Educação, a Ciência e a Cultura (UNESCO). Concluímos que a formação de um novo tipo de homem pelo discurso da autoajuda acontece fora, mas também dentro da escola. Ela contribui para a consolidação de novos padrões de sociabilidade burguesa em tempos de neoliberalismo. Capitalistas, ao longo dos séculos, têm usado a autoajuda para realizar a (con)formação de um novo tipo de força de trabalho.

Palavras-chave: trabalho e educação; autoajuda; hegemonia.

\section{"If you do not change, you will die": a (con)formation of a new type of worker in the discourse of self-help}

This investigation has addressed the ideological aspect of the self-help discourse in the formation of a new type of worker, explaining its role in the construction of hegemony. We studied the principles of this discourse in three periods: its genesis in the nineteenth century, in the early decades of the twentieth century and at the beginning of the twenty-first century. We analyzed how the principles of self-help were reproduced in the Delors and Faure Report. Based on Gramsci and Fairclough, we explained self-help as an ideological discourse present in the reports of the United Nations Educational, Scientific and Cultural Organization (UNESCO). We concluded that the formation of a new type of man by self-help discourse happens not only outside but also inside schools. It contributes to the consolidation of new patterns of bourgeois sociability in times of neoliberalism. For centuries, capitalists have used self-help to perform the (con)formation of a new type of workforce.

Keywords: work and education; self-help; hegemony.

\section{"Si no cambias, morirás": la (con)formación de un nuevo tipo de trabajador en el discurso de autoayuda}

Esta investigación plantea, desde una concepción crítica, las implicaciones del discurso de autoayuda en la formación de un nuevo tipo de trabajador, mediante la explicación de su papel en la construcción de hegemonía. Se estudian los fundamentos de este discurso en tres periodos: su génesis en el siglo XIX, durante las primeras décadas del siglo XX y en los inicios del siglo XXI. Con base en Gramsci y Fairclough, se explica la autoayuda como un discurso ideológico presente en los informes de la UNESCO y se analiza cómo sus fundamentos son reproducidos en el Informe Delors y Faure. Se concluye que la formación de un nuevo tipo de hombre con el discurso de autoayuda, se está dando no solo fuera sino también dentro de la escuela. Asimismo se muestra que este discurso contribuye a la consolidación de nuevos patrones de sociabilidad burguesa en tiempos de neoliberalismo y que los capitalistas, a lo largo del tiempo, han usado la autoayuda para la (con)formación de un nuevo tipo de fuerza de trabajo.

Palabras clave: trabajo y educación; autoayuda; hegemonía. 